\section{Association between levels of physical activity and use of medication among older women}

\author{
Associação entre nível de atividade física e uso de \\ medicamentos entre mulheres idosas
}

\author{
1 Departamento de Medicina \\ Preventiva, Universidade \\ Federal de São Paulo, \\ São Paulo, Brasil. \\ 2 Centro de Estudos do \\ Laboratório de Aptidão Física \\ de São Caetano do Sul, \\ São Caetano do Sul, Brasil. \\ 3 Universidade Federal de \\ Pelotas, Pelotas, Brasil. \\ Correspondence \\ L. J. Silva \\ Centro de Estudos do \\ Laboratório de Aptidão Física \\ de São Caetano do Sul. \\ Rua Heloísa Pamplona 269, \\ São Caetano do Sul, SP \\ 09520-320, Brasil. \\ leonardo@celafiscs.org.br
}

\begin{abstract}
The aim of this study was to determine the association between levels of physical activity and usage of medication in older women. The level of physical activity was assessed using a pedometer. Use of medication was assessed through medical records supplied in reports kept by the Family Health Program, City Health Department, São Caetano do Sul, São Paulo State, Brazil. Regular use of pharmaceuticals, regardless of type of illness or treatment, was listed. Data analysis was performed using Poisson regression to estimate the prevalence ratio. The results of the study indicated that, amongst the 271 eligible women, 84.9\% had been classified as active. Only 23.2\% did not use any type of medication while $29.8 \%$ used three or more medications. The level of physical activity was inversely associated with the number of medications used, under both crude analysis and after adjustment. The study concluded that higher volumes of physical activity were significantly associated with lower usage of pharmaceuticals in women who are involved in a physical activity program.
\end{abstract}

Aging; Physical Activity; Drugs
Leonardo José da Silva 1,2

Mario Renato Azevedo 3

Sandra Matsudo 2

Guiomar Silva Lopes 1

\section{Introduction}

The World Health Organization (WHO) considers physical inactivity to be the fourth leading cause of mortality worldwide ${ }^{1}$. A great amount of effort has been made to minimize the impact of sedentary lifestyles on the public health system which is why physical activity was included in the Global Strategy on Diet, Physical Activity and Health - an agenda released by the WHO in 20042 and, most recently, in a document published by the American Heart Association 3.

In Brazil, there remains little information available regarding the prevalence of physical activity in older individuals (60 or older) which shows the factors that are associated with the level of physical activity 4,5 and health conditions (i.e. presence or absence of disease, health perception and use of medication, among others) and which employs objective techniques to measure levels of physical activity.

Aging alone is a risk factor for a number of diseases, creating the demand for more health care as people grow older. Some studies suggest that increasing levels of physical activity among the population could not only postpone the development of chronic diseases 6 but also generate great savings for healthcare systems 7,8. Medicine consumption, in general, can be an indicator of overall health status 9 , and some studies show that individuals who practice low levels of physical activity may be more likely to consume more medi- 
cation or spend more on health care, as compared to those individuals with higher levels of physical activity 10,11. A recent intervention study showed that the increased physical-activity levels in hypertensive women resulted in a reduction of $28 \%$ on medical consultations, $45 \%$ on examinations and an additional $24.8 \%$ reduction in the use of medication. The savings on vasodilator medicines reached $63.2 \% 12$.

The objective of this study was to analyze the association between physical activity and regular medicinal consumption in elderly women.

\section{Methods}

This study was part of a survey on the levels of physical activity and related health aspects in a sample of the population attended to by community physical-activity programs in São Caetano do Sul, São Paulo State, Brazil. These programs are coordinated by the City Department of Health and have been developed in partnership with the Family Health Strategy (FHS) 13. The city has 15 districts, 11 of which have a health service model with the FHS that covers $66 \%$ of the population.

The 11 districts serviced by the FHS develop community physical-activity programs with all activities guided by physical-education professionals. All of the community physical-activity programs offer similar activities in 60-minute classes, two days a week. The general objectives of said activities are the development of aerobic power as well as an increase and subsequent maintenance of muscle strength, balance and flexibility, all of which are consistent with the recommendations for physical activities 14,15. In each of the 11 physical-activity centers, attendance is taken at the beginning of each class and each participant is required to maintain a minimum $75 \%$ attendance rate each month. Moreover, at the end of each class, the physicaleducation professional provides guidance to the participants for adopting a more active lifestyle during everyday activities. Further details regarding the program may be obtained in a previously published article 16 .

In consideration of the low rate of male participation in the programs, the analyses were restricted to women who met the following eligibility criteria: 60 years of age or older and involved in physical-activity programs coordinated by the FHS, with an attendance rate of $75 \%$ or greater for classes held over the six months prior to data collection. The population studied included all individuals meeting the eligibility criteria.

For the purposes of data collection, health centers were visited between the months of
March and October, 2009, with the interviews being conducted in advance by trained health professionals.

All individuals who participated in the study signed a consent form and met the standards for research involving humans. The project was approved by the Ethics in Research Committee of the Federal University of São Paulo (Universidade Federal de São Paulo - UNIFESP), under protocol number 0956/08, and the Municipal Hospital Complex in São Caetano do Sul, under protocol number 0125/10.

\section{Assessment of physical-activity level}

The physical-activity level was assessed through the number of steps taken using a Yamax Digiwalker (model SW-200, Japan) pedometer. The protocol for pedometer use was proposed by Tudor-Locke et al. 17 and consisted of wearing the pedometers at the waistline (iliac crest), for seven consecutive days. In addition to the pedometer, subjects were provided with written instructions on its use and a seven-day diary in which to record the dates and times the device was worn, the time it was taken off and the total number of steps recorded during each day.

The average daily use was 10 hours/day. Pickup and delivery of the measuring instruments were always performed during the first lesson of the week.

The physical-activity cutoff points for the scores were based on recommendations for the number of steps with "insufficiently active" being up to 5,999 steps, "active" falling between 6,000 and anything over 8,500 steps being considered "very active" 18.

\section{Assessing medicine use}

The number of medications consumed was measured by reviewing the medical records of FHS, prioritizing medicines prescribed on the most recent visit to the doctor and considering only the regular use of medications for treatment of non-communicable chronic diseases (NCDs).

Self-medication was not considered in the present study. The frequency of use of medicines and their dosages were also not explored.

\section{Additional independent variables}

The following independent variables were collected:

- Age: years, later categorized;

- Ethnicity: observed by the interviewer;

- Schooling: years of study, further categorized;

- Smoking: regular consumption of cigarettes; 
- Body mass index (BMI): weight (kg) divided by the square of height (meters), further categorized according to the criterion of normal $\left(<26 \mathrm{~kg} / \mathrm{m}^{2}\right)$ and overweight ( $>26 \mathrm{~kg} / \mathrm{m}^{2}$ );

- Number of falls in the last year: self reported;

- Alcohol consumption: the usual frequency $\geq$ than twice a week;

- Diagnosis of diabetes: from medical records;

- Diagnosis of hypertension: from medical records;

- Abdominal circumference: normal $(<0.80 \mathrm{~cm})$ and risk $(>0.80 \mathrm{~cm})$;

- Waist-hip ratio: normal $(<0.90 \mathrm{~cm})$ and risk $(>0.90 \mathrm{~cm})$;

- Bone fracture in the last year: self-reported;

- Sitting time: average weekly time (hours/day) independent of activity (occupational, leisure and transport).

\section{Statistical analysis}

Descriptive analysis is shown (proportions for categorical data and means, with standard deviations). Crude analyses between the level of physical activity and independent variables were conducted using the chi-square test for heterogeneity (categorical variables) and linear trend (ordinal variables). A Poisson regression 19,20 was used to adjust for potential confounding factors.

The final model was composed of variables with $\mathrm{p}<0.20$ in the adjusted analysis. The effect of physical activity on the use of medication was initially adjusted for age and ethnicity. Later, education was included as a potential confounder. Finally, the following variables were added to be tested in the model: fracture in the last year, falling in the last year, alcohol intake, smoking, diabetes, hypertension, waist circumference, waist-hip ratio and sitting time. The level of significance was set to $\mathrm{p}<0.05$. All tests were performed in Stata statistical package, version 10.0 (Stata Corp., College Station, USA).

\section{Results}

The data analyzed were collected from the 271 eligible women, 60 years of age or older and involved in physical-activity programs coordinated by the FHS, with an attendance rate greater than, or equal to, $75 \%$ of the classes over the six months immediately prior to data collection. The population studied included all individuals (100\%) meeting the eligibility criteria. The study sample had a mean of 26.6 months (SD 8.4, minimum 7.0 and maximum 46.6 months) of participation in physical-activity programs coordinated by the FHS in the city of São Caetano do Sul.
The mean age of the sample was 68.6 years (SD 7.1, minimum 60 and maximum 91 years), BMI, was $28.2 \mathrm{~kg} / \mathrm{m}^{2}$ (SD 12.2).

Table 1 presents the description of the sample for all variables and their association with physical-activity level. The women were mostly Caucasian $(72.7 \%)$. The prevalence of hypertension was $44.7 \%$ with that of diabetes at $18.1 \%$. A total of $15.1 \%$ of the women in the sample were classified as insufficiently active. Nearly one quarter $(23.2 \%)$ did not use any kind of medication while $29.9 \%$ used three or more medicines. Upon analyzing the associations with physical activity, women who did not consume medications, including those with schooling of between 0 and 2 years, were more active $(\mathrm{p} \leq 0.001$ and 0.003 , respectively).

Medications for cardiovascular (36.5\%), nervous system (13.5\%), endocrine system (12.6\%), gastrointestinal tract (18.3\%), musculoskeletal (11.9\%) and respiratory diseases $(6.9 \%)$ were the most used.

Figure 1 demonstrates that the higher the level of physical activity, the lower the frequency of medicine utilization ( $\mathrm{p}<0.001$ ). The proportions of medicine use were $100 \%$ among insufficiently active individuals ( $<6,000$ steps per day), $88.6 \%$ in active individuals (6,000 to 8,500 steps per day) and $69.3 \%$ among very active individuals $(>8,500$ steps per day).

Figure 2 shows the relationship between the number of medicines used and level of physical activity. The proportion of individuals using four or more medications was higher among insufficiently active subjects $(\mathrm{p}<0.001)$. High levels of physical activity were associated with lower medicinal consumption.

Table 2 presents the crude and adjusted analyses of the association between physical-activity level and medication usage. After adjustment for confounders, the level of physical activity was inversely associated with medicinal use. The most active group (> 8,500 steps / day) presented a $47 \%$ lower prevalence when compared to sedentary individuals.

\section{Discussion}

To the best of our knowledge, this is the first study to examine this kind of association using an objective measure of physical activity and finding an inverse association between physical activity and medicinal consumption, even after controlling for confounders.

A Brazilian population-based study 21, with 3,182 individuals who responded to the International Physical Activity Questionnaire (IPAQ 
Description of the sample in terms of demographic and socioeconomic variables, physical activity and medicine use. São Caetano do Sul, São Paulo State, Brazil, 2009.

\begin{tabular}{|c|c|c|c|c|}
\hline Variables & $\mathrm{n}$ & $\%$ & Active \% & $p$-value \\
\hline Age (years) & & & & $0.570 * ; 0.973$ ** \\
\hline $60-64$ & 90 & 33.21 & 86.7 & \\
\hline $65-74$ & 125 & 46.13 & 82.4 & \\
\hline$\geq 75$ & 56 & 20.66 & 87.5 & \\
\hline Ethnicity & & & & 0.058 * \\
\hline Caucasian & 191 & 70.48 & 82.20 & \\
\hline Non-Caucasian & 80 & 29.52 & 91.25 & \\
\hline Schooling (years) & & & & $0.003 * ; 0.360$ ** \\
\hline $0-2$ & 105 & 38.8 & 91.43 & \\
\hline $3-4$ & 90 & 33.2 & 74.44 & \\
\hline $5+$ & 76 & 28.04 & 88.16 & \\
\hline Bone fracture & & & & 0.152 * \\
\hline Yes & 240 & 88.56 & 83.75 & \\
\hline No & 31 & 11.44 & 93.55 & \\
\hline Falls in the last year & & & & 0.454 * \\
\hline Yes & 171 & 63.10 & 83.63 & \\
\hline No & 100 & 36.90 & 87.00 & \\
\hline Alcohol intake & & & & 0.224 * \\
\hline Never & 125 & 46.13 & 80.80 & \\
\hline Former & 68 & 25.09 & 88.24 & \\
\hline Current & 78 & 28.78 & 88.46 & \\
\hline Smoking & & & & 0.601 * \\
\hline Yes & 232 & 85.61 & 85.3 & \\
\hline No & 39 & 14.39 & 82.1 & \\
\hline Medicine use & & & & $<0.001$ * \\
\hline Yes & 208 & 76.75 & 100.0 & \\
\hline No & 63 & 23.25 & 80.29 & \\
\hline Diabetes & & & & 0.856 * \\
\hline Yes & 222 & 81.92 & 84.68 & \\
\hline No & 49 & 18.08 & 85.71 & \\
\hline Hypertension & & & & 0.560 * \\
\hline Yes & 150 & 55.35 & 86.00 & \\
\hline No & 121 & 44.65 & 83.47 & \\
\hline Abdominal circumference $(\mathrm{cm})$ & & & & 0.807 * \\
\hline$<80$ & 77 & 28.41 & 85.71 & \\
\hline$\geq 80$ & 194 & 71.59 & 84.54 & \\
\hline $\mathrm{BMI}\left(\mathrm{kg} / \mathrm{m}^{2}\right)$ & & & & 0.479 * \\
\hline$<26$ & 106 & 39.11 & 86.79 & \\
\hline$\geq 26$ & 165 & 60.89 & 83.64 & \\
\hline Waist-hip ratio (cm) & & & & 0.653 * \\
\hline$<0.90$ & 101 & 37.27 & 86.14 & \\
\hline$\geq 0.90$ & 170 & 62.73 & 84.12 & \\
\hline Sitting time & & & & $0.124 * ; 0.125$ ** \\
\hline 1st Tertile & 106 & 39.11 & 86.79 & \\
\hline 2nd Tertile & 88 & 32.47 & 88.64 & \\
\hline 3rd Tertile & 77 & 28.41 & 77.92 & \\
\hline Total & 271 & 100.00 & 84.87 & \\
\hline
\end{tabular}

BMI: body mass index.

* Chi-square test for heterogeneity;

** Chi-square test for linear trend. 


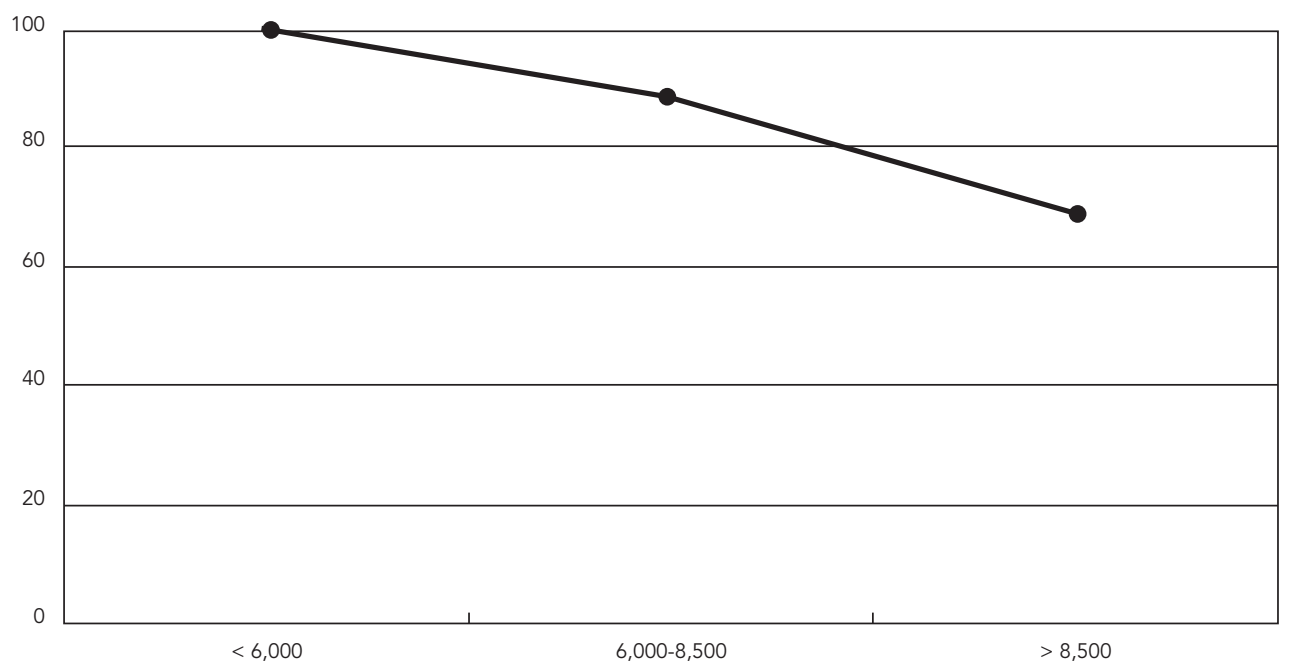

$\mathrm{p}<0.001$

Figure 2

Association between physical activity level and number of medicines used in women. São Caetano do Sul, São Paulo State, Brazil, 2009

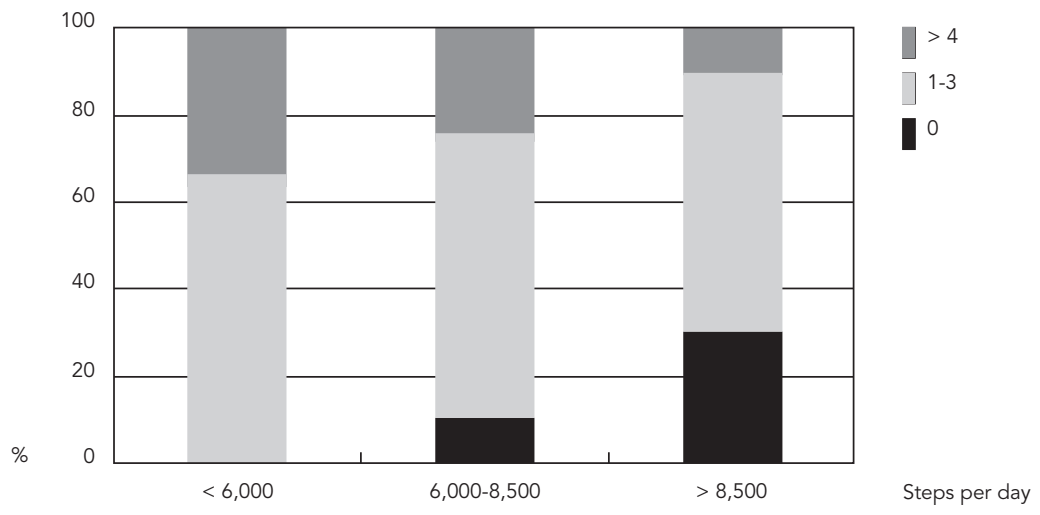

- short version) and self-reported medicine consumption, found (unadjusted analysis) that sedentary individuals consumed $23 \%$ more medicines than the most active individuals. In the present study, this difference was of $55 \%$. After adjustment, in both studies this difference decreased though remained significant $(\mathrm{p}<0.001$; $13 \%$ and $47 \%$, respectively).

In our analysis, the effect of physical activity on medication use remained significant, even 
Multivariable analyses of the association between medicine use and physical activity level in women physically independent. São Caetano do Sul, São Paulo State, Brazil, 2009

\begin{tabular}{|c|c|c|c|c|}
\hline Variables & $\begin{array}{l}\text { PR crude analysis } \\
\qquad(95 \% \mathrm{Cl})\end{array}$ & p-value & PR adjusted $(95 \% \mathrm{CI})$ * & p-value \\
\hline Physical activity level (steps/day) & & $<0.001 * \star ;<0.001 * \star \star$ & & $<0.001^{\star \star} ;<0.001^{\star \star \star *}$ \\
\hline$<6,000$ & 1.00 & & 1.00 & \\
\hline $6,001-8,500$ & $0.81(0.59-1.10)$ & & 0.87 (0.69-1.09) & \\
\hline$>8,500$ & $0.45(0.34-0.59)$ & & $0.53(0.43-0.65)$ & \\
\hline
\end{tabular}

PR: prevalence ratio; $95 \% \mathrm{Cl}$ : $95 \%$ confidence interval.

* Adjusted for age, ethnicity, education, fracture in the last year, falling last year, alcohol intake, smoking, diabetes, hypertension, waist circumference, waist-hip ratio, BMI, sitting time;

** Wald test for heterogeneity;

*** Wald test for linear trend.

after adjusting for confounders. The significant association found in this study cannot be understood as a possible residual confounding. The fact that the adjusted analysis did not provide results differing from those obtained in the crude analysis minimizes the likelihood of residual confounding.

In the multinational study Monitoring of Trends and Determinants in Cardiovascular Disease project (MONICA) 22, the risk of developing hypertension decreased linearly as the level of leisure-time physical activity increased, among both men and women. Men with high leisuretime physical activity had a, statistically, significantly reduced risk of hypertension, even after adjustment for age, education, smoking, alcohol intake and body mass index [hazard ratio (HR) 0.79 ; 95\% confidence interval (CI) 0.63 to 0.99 ].

The reduction in blood pressure induced by the chronic effect of physical activity (hypotensive effect) has been attributed to lower systemic vascular resistance 23 caused by reduced sympathetic activity. Other hypotheses suggest that the reduction of plasma rennin activity, reduced concentrations of catecholamines 24 , urinary sodium excretion and increased insulin sensitivity 25 may be influenced by the engagement in regular physical activity. In fact, physical training has been shown to trigger an improvement in the production of endothelium-dependent vasodilator substances 26,27 .

Among previously published studies, one of the limitations is the fact that self report was used to measure medicinal consumption $28,29,30$, thus becoming more likely to be affected by recall bias among older people ${ }^{31}$. In the present study, this problem was not present as medical records were used.
Another strong point of this study is that the assessment of physical activity was carried out by an objective instrument. In the elderly, these questionnaires are subject to recall errors which interfere with the estimated duration of activities during the week 32 . Furthermore, as was the case in this study, when evaluating overall physical activity, the overestimation of data on physical activity in domestic and work environments is a problem ${ }^{33}$

Some limitations in this study must be considered. First, the cross-sectional nature of data collecting does not allow us to establish causal relationships between physical activity and medicinal consumption. On one hand, we expect that individuals who become active shall improve overall health and reduce medicine consumption. The fact is that subjects with a history of healthy habits such as regular physical activity, healthy eating and lower alcohol intake can enjoy additional benefits by slowing the rise of chronic diseases and thus decreasing the chances of high medication consumption 34 .

Family income data were missing (family gross income, in Reais) for 171 elderly (63.1\%) in the sample. However, an exploratory analysis was carried out among individuals who informed their income and we did not find evidence of association with physical activity or medication use. Thus, it was excluded from the final model.

In relation to the sample, it is worth noting that all women were engaged in physical activity sponsored by the FHS. Thus, while extrapolation of results to the general population should be performed with caution, the findings show that even for those who are active, physical-activity levels may represent an important impact on medicine consumption. 


\section{Conclusion}

Higher levels of physical activity were significantly associated with lower use of medication in women engaged in a physical-activity program and public healthcare users. These findings suggest that involvement in physical activity can help to reduce medicinal use among elderly women who are functionally independent.

\section{Resumo}

O objetivo deste estudo foi avaliar a associação entre o nível de atividade física e uso de medicamentos em mulheres com 60 anos de idade ou mais. O nível de atividade física foi avaliado utilizando pedômetro. O consumo de medicamento foi avaliado mediante o prontuário de cadastro da Estratégia Saúde da Família em São Caetano do Sul, São Paulo, Brasil. Foram registrados os medicamentos de uso regular independente do tipo da doença ou do tratamento. Foi realizada análise de regressão de Poisson para estimar a razão de prevalências. Das 271 mulheres elegíveis, $84,9 \%$ foram classificadas como ativas. Apenas $23,2 \%$ não utilizam nenhum tipo de medicamento, enquanto 29,8\% utilizaram três ou mais medicamentos. O nível de atividade física foi inversamente associado com o número de medicamentos utilizados tanto na análise bruta como na ajustada. Maiores volumes de atividade física associaram-se significativamente com menor consumo de medicamentos em mulheres envolvidas em um programa de atividade física.

Envelhecimento; Atividade Física; Medicamentos

\section{Contributors}

L. J. Silva and S. Matsudo coordinated data collection and lead the writing of the manuscript. M. R. Azevedo and L. J. Silva coordinated the analysis and interpretation of data. G. S. Lopes performed the technical review of the manuscript and approved the final version.

\section{Acknowledgments}

We would like to thank Juliana Bellini, João Pedro da Silva Junior, Rosangela Villa Marin and Mauricio dos Santos for their assistance in the process of gathering information regarding the physical-activity program. This study was sponsored by the FAPESP (process no. 2009/03271-0). The funding agency had no role in study design. 


\section{References}

1. World Health Organization. Global health risks: mortality and burden of disease attributable to selected major risks. Geneva: World Health Organization; 2009.

2. World Health Organization. Global strategy on diet, physical activity and health. Geneva: World Health Organization; 2004.

3. Artinian NT, Fletcher GF, Mozaffarian D, KrisEtherton P, Van Horn L, Lichtenstein AH, et al. Interventions to promote physical activity and dietary lifestyle changes for cardiovascular risk factor reduction in adults. A scientific statement from the American Heart Association. Circulation 2010; 122:406-41.

4. Mazo G, Mota J, Gonçalves L, Matos M. Nível de atividade física, condições de saúde e características sócio-demográficas de mulheres idosas brasileiras. Rev Port Ciênc Desporto 2005; 5:202-12.

5. Hallal PC, Victora CG, Wells JCK, Lima RC. Physical inactivity: prevalence and associated variables in Brazilian adults. Med Sci Sports Exerc 2003; 35:1894-900.

6. Thune I, Brenn T, Lund E, Gaard M. Physical activity and the risk of breast cancer. N Engl J Med 1997; 336:1269-75.

7. Oldridge NB. Economic burden of physical inactivity: healthcare costs associated with cardiovascular disease. Eur J Cardiovasc Prev Rehabil 2008; 15:130-9.

8. Wang W, McGreevey WP, Fu C. Type 2 diabetes mellitus in China: a preventable economic burden. Am J Manag Care 2009; 15:593-601.

9. Neutel CI. Drug utilization patterns as indicators. Pharmacoepidemiol Drug Saf 1998; 7:131-3.

10. Anderson LH, Martinson BC, Crain AL, Pronk NP, Whitebird RR, Fine LJ, et al. Health care charges associated with physical inactivity, overweight, and obesity. Prev Chronic Dis 2005; 2:1-12.

11. Pillman BCS, Ubitz JL. The effect of longevity on spending for acute and long-term care. $\mathrm{N}$ Engl J Med 2000; 342:1409-15.

12. Rolim LMC, Amaral SL, Monteiro HL. Hipertensão e exercício: custos do tratamento ambulatorial, antes e após a adoção da prática regular e orientada de condicionamento físico. Hipertensão 2007; 10:54-61.

13. Departamento de Atenção Básica, Secretaria de Políticas de Saúde, Ministério da Saúde. Programa Saúde da Família. Rev Saúde Pública 2000; 34:316-9.

14. Nelson MF, Rejeski J, Blair SN, Duncan PW, Judge JO, King AC, et al. Physical activity and public health in older adults. Recommendation from the American College of Sports Medicine and the American Heart Association. Circulation 2007; 116:2-12.

15. Haskell WL, Lee I-M, Pate RR, Powell KE, Blair SN, Franklin BA, et al. Physical activity and public health: updated recommendation for adults from the American College of Sports Medicine and the American Heart Association. Circulation 2007; 116:1081-93
16. Silva L, Matsudo S, Lopes G. Do diagnóstico à ação: Programa comunitário de atividade física na atenção básica: a experiência do município de São Caetano do Sul, Brasil. Rev Bras Ativ Fís Saúde 2011; 16:84-8.

17. Tudor-Locke C, Lind K, Reis JP, Ainsworth BE, Macera CA. A preliminary evaluation of a pedometerassessed physical activity self-monitoring survey. Field Methods 2004; 16:422-38.

18. Masurier G. Walk which way? ACSM'S Health \& Fitness Journal 2004; 8:7-10.

19. Barros AJ, Hirakata VN. Alternatives for logistic regression in cross-sectional studies: an empirical comparison of models that directly estimate the prevalence ratio. BMC Med Res Methodol 2003; 3:21-33.

20. Dumith SC. Proposta de um modelo teórico para a adoção da prática de atividade física. Rev Bras Ativ Fís Saúde 2008; 13:110-20.

21. Bertoldi AD, Hallal PC, Barros AJD. Physical activity and medicine use: evidence from a populationbased study. BMC Public Health 2006; 6:224-9.

22. Barengo N, Hu G, Kastarinen M, Lakka TA, Pekkarinen $\mathrm{H}$, Nissinen A, et al. Low physical activity as a predictor for antihypertensive drug treatment in 25-64-year-old populations in Eastern and southwestern Finland. J Hypertens 2005; 23:293-9.

23. Bond V, Franks BD, Tearney RJ, Wood B, Melendez MA, Johnson L. Exercise blood pressure response and skeletal muscle vasodilator capacity in normotensives with positive and negative family history of hypertension. J Hypertens 1994; 12:285-90.

24. Dubbert PM, Martin JE, Cushman WC, Meydrech EF, Carroll RG. Endurance exercise in mild hypertension: effects on blood pressure and associated metabolic and quality of life variables. J Hum Hypertens 1994; 8:265-72.

25. Arakawa K. Antihypertensive mechanism of exercise. J Hypertens 1993; 11:223-9.

26. Hambrecht R, Fiehn E, Weigl C, Gielen S, Hamann C. Regular physical exercise corrects endothelial dysfunction and improves exercise capacity in patients with chronic heart failure. Circulation 1998; 98:2709-15.

27. Hambrecht R, Wolf A, Gielen S, Linke A, Hofer J, Erbs S, et al. Effect of exercise on coronary endothelial function in patients with coronary artery disease. N Engl J Med 2000; 342:454-60.

28. Bertoldi AD, Barros AJ, Hallal PC, Lima RC. Drug utilization in adults: prevalence and individuals determinants. Rev Saúde Pública 2004; 38:228-38.

29. Williams PT. Relationship of running intensity to hypertension, hypercholesterolemia, and diabetes. Med Sci Sports Exerc 2004; 40:1740-8.

30. Ungar W. Bias - It's everywhere! A commentary on the impact of bias and the assessment of agreement in the measurement of medication use in epidemiology research. Pharmacoepidemiol Drug Saf 1998; 7:425-7. 
31. Heesch KC, van Uffelen JGZ, Hill RL, Brown WJ. What do IPAQ questions mean to older adults? Lessons from cognitive interviews. Int J Behav Nutr Phys Act 2010; 7:35-48.

32. Hallal PC, Gómez LF, Parra DC, Lobelo F, Mosquera J, Florindo AA, et al. Lessons learned after 10 years of IPAQ use in Brazil and Colombia. J Phys Act Health 2010; 7 Suppl 2:259-64.

33. Gillies CL, Abrams KR, Lambert PC, Cooper NJ, Sutton AJ, Hsu RT, et al. Pharmacological and lifestyle interventions to prevent or delay type 2 diabetes in people with impaired glucose tolerance: a systematic review and meta-analysis. BMJ 2007; 334:299-308.

34. Slentz CA, Houmard JA, Kraus WE. Modest exercise prevents the progressive disease associated with physical inactivity. Exerc Sport Sci Rev 2007; 35: 18-23.

Submitted on 03/Mar/2011

Final version resubmitted on 13/Oct/2011

Approved on 20/Oct/2011 